\title{
Examining the side effects of sucrose for pain relief in preterm infants: a case-control study
}

\author{
M.B.M. Linhares ${ }^{1}$, C.M. Gaspardo ${ }^{1}$, L.O. Souza ${ }^{1}$, B.O. Valeri ${ }^{1}$ and F.E. Martinez ${ }^{2}$ \\ ${ }^{1}$ Departamento de Neurociências e Ciências do Comportamento, Faculdade de Medicina de Ribeirão Preto, \\ Universidade de São Paulo, Ribeirão Preto, SP, Brasil \\ ${ }^{2}$ Departamento de Puericultura e Pediatria, Faculdade de Medicina de Ribeirão Preto, Universidade de São Paulo, \\ Ribeirão Preto, SP, Brasil
}

\begin{abstract}
Sucrose solution is recommended as relevant pain relief management in neonates during acute painful procedures; however, only a few studies have analyzed the potentially adverse effects of sucrose administration to preterm neonates. The goal of this study was to examine the potential side effects of sucrose for pain relief in preterm infants, assessing feeding and weight gain during hospitalization and their feeding patterns postdischarge. The study sample consisted of 43 preterm neonates divided into two groups: a sucrose group (SG, $n=18$ ) and a control group (CG, $n=25)$ in which no sucrose was administered. The SG received $0.5 \mathrm{~mL} / \mathrm{kg} 25 \%$ oral sucrose for 2 min prior to all acute painful procedures during three consecutive days. A prospective review of medical charts was performed for all samples. The study was done prior to implementation of the institutional sucrose guidelines as a routine service, and followed all ethical requirements. There were no statistically significant differences between groups in terms of weight gain, length of stay with orogastric tubes, and parenteral feeding. Postdischarge, infant nutritional intake included feeding human milk to $67 \%$ of the SG and $74 \%$ of the CG. There were no statistically significant differences between groups regarding human milk feeding patterns postdischarge. Neonate feeding patterns and weight gain were unaffected following the short-term use of sucrose for pain relief.
\end{abstract}

Key words: Sucrose; Pain relief; Side effects; Feeding; Preterm

\section{Introduction}

Preterm neonates show cortical $(1,2)$, biochemical (3), physiological $(4,5)$, and behavioral $(6,7)$ responses to painful procedures. Nonpharmacological management has been recommended for pain relief, such as nonnutritive sucking (8), breastfeeding $(9,10)$, skin-to-skin contact $(11,12)$, and sweetened solutions, including glucose (13), fructose (14), and sucrose (15-19).

Sucrose solution is recommended as relevant pain relief management in neonates during acute painful procedures $(19,20)$ and is included in the pain guidelines of Neonatal Intensive Care Units (NICUs) (21-23). The efficacy of oral sucrose solution for pain relief in preterm neonates was established as a single dose 2 min prior to acute painful procedures, using $2 \mathrm{~mL} 25 \%$ sucrose $(24,25)$. Additionally, the effectiveness of sucrose solution for pain relief has been established by scheduled administration of repeated doses during the same painful procedure $(26,27)$ and on consecutive days $(16,18,28-30)$.

However, only a few studies with inconclusive findings have analyzed the potentially adverse effects of scheduled administration of sucrose solution in repeated doses on the developmental and clinical status of preterm neonates $(16,18,28,31)$. In one study, high-risk preterm infants using high doses of sucrose ( $\geq 10$ per day) for pain relief showed low neurobehavioral development scores at 36 and 40 weeks postconception (28). In another, preterm infants also using sucrose exhibited normal development at 28 days postnatal age in comparison with control group given sterile water (18). In addition, no adverse effects of sucrose on clinical outcomes (i.e., occurrence of residues in the stomach, vomiting, and abdominal distension) were detected in preterm infants during the first and second postnatal weeks

Correspondence: M.B.M. Linhares, Departamento de Neurologia, Psiquiatria e Psicologia Médica, Faculdade de Medicina de Ribeirão Preto, USP, Av. Tenente Catão Roxo, 2650, Prédio da Saúde Mental (Salas 52/53), 14048-900 Ribeirão Preto, SP, Brasil. Fax: +5516-3602-4504. E-mail: linhares@fmrp.usp.br

Received November 9, 2013. Accepted February 27, 2014. First published online May 2, 2014. 
(18). Other potentially adverse effects include the alteration of glucose homeostasis, specifically hyperglycemia, but this is more of a theoretical adverse effect than a welldocumented one (17).

To date, this is the first study analyzing the association of repeated doses of sucrose for acute pain relief management with the feeding patterns and weight gain of preterm infants. The aim of the present study was to examine the potential short-term side effects of using sucrose for pain relief on feeding patterns and weight gain of preterm infants during hospitalization and immediately postdischarge.

\section{Material and Methods}

\section{Study design}

The present study was a case-control study, with analysis of between-group differences. The sample comprised 43 preterm ( $<37$ weeks gestational age) and very low birth weight $(<1500 \mathrm{~g})$ neonates who were hospitalized in the NICU of Hospital das Clínicas, Faculdade de Medicina de Ribeirão Preto, Universidade de São Paulo (Brazil). The neonates who had major congenital anomalies, intraventricular hemorrhage (grade III/IV), and hypoglycemia or hyperglycemia, or who were on opioid or sedative medications and an umbilical catheter in the first and second weeks of life were excluded.

The sample was divided into two groups: a sucrose group (SG) and a control group (CG). The SG included 18 neonates, of which 17 participants corresponded to secondary data of a randomized controlled trial study previously published that examined the analgesic effects and short-term adverse effects of repeated doses of sucrose over a 3-day period (18). The SG neonates received $0.5 \mathrm{~mL} / \mathrm{kg} 25 \%$ oral sucrose 2 min before the following acute painful procedures: venipuncture, arterial puncture, heel lancing, intravenous cannulation, endotracheal tube introduction, endotracheal tube suctioning, gavage insertion for feeding, and the removal of electrode leads and tape. These procedures were selected based on the study of Johnston et al. (28), and the neonates received an average of six doses of sucrose per day (18).

The CG was composed of 25 neonates, who were hospitalized in the NICU at the same time as the SG, but they were immediately transferred to the Intermediary Special Care Nursery depending on the evolution of their clinical status. The CG did not receive sucrose during acute painful procedures. At the time of data collection, the great majority of studies had tested single doses of sucrose for pain relief (32). Then, a randomized controlled trial was carried out to examine the efficacy and side effects of repeated doses of a sucrose schedule (3-day period) for acute pain relief (18). We then collected data from the $C G$, because the pain management guidelines using sucrose had not yet been implemented.

\section{Ethics approval}

The Clinical Research Ethics Board of Hospital das Clínicas, Faculdade de Medicina de Ribeirão Preto, Universidade de São Paulo, Brazil, approved the present study. Informed written consent was obtained from all parents of the patients in the study prior to participation. This study was done prior to the implementation of sucrose for acute pain relief management as a routine clinical guideline in the NICU.

\section{Measurements and procedure}

Medical chart reviews were performed using a protocol for data collection by trained researchers. Infant characteristics and their clinical evolution were obtained. The main variables for analyzing the side effects of sucrose were the following: a) parenteral feeding, duration of orogastric tube use, weight at 38 weeks postconception, weight at discharge, weight gain between birth and 38 weeks postconception, and weight gain between birth and discharge (during hospitalization); and $b$ ) feeding pattern using human milk (postdischarge).

\section{Data analysis}

The Statistical Package for the Social Sciences (version 19.0, USA) was used for data analysis. The Shapiro-Wilk test was used to verify the normal distribution of the data, and, according to the results, a nonparametric statistical approach was adopted. The between-group comparisons (SG vs CG) were analyzed using the Mann-Whitney test for continuous variables and the chi-square test for categorical variables. The statistical significance level for all tests in this study was set at $\mathrm{P} \leq 0.05$.

\section{Results}

\section{Characteristics of preterm infants and neonatal health status}

The characteristics and clinical status of the preterm infants are reported in Table 1. There were no statistically significant differences between groups with regard to the following variables: gender, gestational age, neonatal clinical risk index, five-minute Apgar score, necrotizing enterocolitis, and length of stay in the hospital. However, the SG presented significantly lower birth weight than the CG.

\section{Feeding and weight gain outcomes during hospitalization and postdischarge}

The feeding patterns and weight gain of preterm neonates during hospitalization and postdischarge are reported in Table 2 . There were no statistically significant differences between the $S G$ and $C G$ with regard to administration of parenteral feeding, duration of orogastric tube use, average weight at 38 weeks postconception and at discharge, weight gain between birth and 38 weeks postconception, and weight gain between birth and discharge. 
Table 1. Characteristics of preterm infants.

\begin{tabular}{|c|c|c|}
\hline Infant characteristics and neonatal health status & $S G(n=18)$ & $C G(n=25)$ \\
\hline \multicolumn{3}{|l|}{ Gender $^{1}$} \\
\hline Male & $7(39)$ & $14(58)$ \\
\hline Female & $11(61)$ & $11(42)$ \\
\hline Gestational age $^{2}$ (weeks) & $30 \pm 2$ & $31 \pm 2$ \\
\hline Birth weight $^{2}(\mathrm{~g})$ & $1027 \pm 250$ & $1201 \pm 210^{*}$ \\
\hline \multicolumn{3}{|l|}{ Appropriateness for gestational age ${ }^{1}$} \\
\hline Small for gestational age & $8(44)$ & $17(68)$ \\
\hline Appropriate for gestational age & $10(56)$ & $8(32)$ \\
\hline $\mathrm{CRIB}^{2}$ (score) & $4 \pm 3$ & $3 \pm 4$ \\
\hline Apgar $5^{\text {th }} \min ^{2}$ (score) & $8 \pm 1$ & $8 \pm 2$ \\
\hline Necrotizing enterocolitis ${ }^{1}$ & $1(5)$ & 0 \\
\hline Length of stay in hospital ${ }^{2}$ (days) & $61 \pm 25$ & $53 \pm 19$ \\
\hline
\end{tabular}

Data are reported as means \pm SD or number with percent in parentheses. SG: sucrose group; CG: control group. CRIB: clinical risk index for babies. ${ }^{1}$ Chi-square test; ${ }^{2}$ Mann-Whitney test $\left({ }^{*} \mathrm{P}<0.05\right)$.

There were no statistically significant differences between groups in the postdischarge patterns for feeding with human milk. Sixty-seven percent of the SG infants and $74 \%$ of the CG infants were fed with human milk, either by exclusive breastfeeding or by formula supplementation.

\section{Discussion}

The findings of the present study showed that the preterm infants who received sucrose for acute pain relief in the NICU did not present adverse side effects in terms of their feeding patterns and weight gain. The SG presented a clinical evolution similar to the CG with regard to the duration of orogastric tube use, administration of parenteral feeding, and weight gain. In addition, the majority of the infants in the SG left the hospital being fed human milk, either by exclusive breastfeeding or with formula supplementation.

The indirect measurement of feeding tolerance was the time at which the infants received parenteral nutrition.
Parenteral feeding is the recommended choice for the initial nutritional management of high-risk preterm infants, which leads to elevated costs for the healthcare system (33). In the clinical guidelines of the NICU in the current study, the preterm infants received parenteral feeding during the period when they did not tolerate enteral feeding. The tolerance of preterm infants for human milk was the main factor in deciding whether to make the transition from parenteral to enteral feeding. The similar duration of parenteral feeding in the two groups suggests that there was a similar feeding pattern in the evolution of these infants. The use of sucrose for pain relief in preterm infants did not influence dietary progression during hospitalization in the NICU.

Another concern is whether the repeated doses of sucrose that are used for pain relief provoke conditioning responses in preterm infants through association between the pleasant sweet taste and aversive painful stimuli. Studies have demonstrated evidence of potential conditioning responses in preterm neonates during painful or

Table 2. Feeding pattern and weight gain outcomes of preterm infants.

\begin{tabular}{|c|c|c|}
\hline Feeding pattern and weight gain & SG & CG \\
\hline During hospitalization & $(n=18)$ & $(n=25)$ \\
\hline Orogastric tube use ${ }^{2}$ (days) & $51 \pm 27$ & $42 \pm 21$ \\
\hline Parenteral feeding ${ }^{2}$ (days) & $11 \pm 8$ & $9 \pm 5$ \\
\hline Weight at 38 weeks of postconceptional age $\mathrm{e}^{2}(\mathrm{~g})$ & $1891 \pm 359$ & $1946 \pm 319$ \\
\hline Weight at discharge ${ }^{2}(\mathrm{~g})$ & $2057 \pm 314$ & $2167 \pm 359$ \\
\hline Weight gain between birth and 38 weeks of postconceptional age ${ }^{2}(\mathrm{~g})$ & $881 \pm 316$ & $739 \pm 296$ \\
\hline Weight gain between birth and discharge ${ }^{2}(\mathrm{~g})$ & $1000 \pm 417$ & $1014 \pm 632$ \\
\hline Post-discharge & $(n=17)$ & $(n=19)$ \\
\hline Human milk feeding number of neonates ${ }^{1}(\%)$ & $12(67 \%)$ & $14(74 \%)$ \\
\hline
\end{tabular}

Data are reported as means \pm SD or number with percent in parentheses. SG: sucrose group; CG: control group. ${ }^{1}$ Chi-square test; ${ }^{2}$ Mann-Whitney test $(\mathrm{P}>0.05)$. 
stressful procedures (34-36). If these learning conditioning mechanisms were established, the high-risk preterm infants could exhibit avoidance of oral sweet solutions during feeding, such as human milk.

Our results also do not confirm this association between the use of sucrose and avoidance of sweet feeding, and the two groups of preterm infants exhibited similar feeding patterns. There was a wide range in the duration of orogastric tube use in the sample study, but there were no differences between the SG and CG. In general, the duration of orogastric tube use in the NICU is associated with maturity levels of the infants with regard to their capacities for breathing, feeding, and swallowing; the lower the gestational age of the infants, the lower the coordination of these capacities, and, consequently, the longer the duration of orogastric tube use during hospitalization (37). Human milk tastes sweet and contains $7 \%$ sucrose. If there was a conditioned association, the preterm infants who received sucrose for pain relief could present avoidance to being fed human milk. Our findings did not confirm this association between sweet solutions and aversive stimuli; the percentage of preterm SG infants who accepted human milk was similar to those in the CG.

A recent study that evaluated the effects of breastfeeding for reducing minor procedural pain during NICU hospitalization did not show efficacy for pain relief in preterm infants born at 30-36 weeks gestational age, compared with a control group given soothing procedures (10). In addition, when pairing breastfeeding with a single blood collection, there were no adverse effects detected on immediate breastfeeding behavior, within the $24 \mathrm{~h}$ after the painful procedure. Our findings add to this previous study, in the sense that we examined the feeding pattern outcomes, including the days on parenteral nutrition and orogastric feeding, besides breastfeeding. In addition, we analyzed the feeding pattern during the entire time the infants were hospitalized and postdischarge, in addition to the length of time in the NICU.

Although many factors are involved in the growth of preterm infants, undoubtedly nutrition is one of the most relevant. The fact that the groups presented similar growth is a strong indication that they ingested similar quantities of nutrients. The diet offered to all infants was the same. It was initiated with early parenteral nutrition on the first day, which was maintained for the shortest possible time, depending on the acceptance of human milk. Although the pace of growth was a little slower with

\section{References}

1. Bartocci M, Bergqvist LL, Lagercrantz $H$, Anand KJ. Pain activates cortical areas in the preterm newborn brain. Pain 2006; 122: 109-117, doi: 10.1016/j.pain.2006.01.015.

2. Slater R, Cantarella A, Gallella S, Worley A, Boyd S, Meek J, et al. Cortical pain responses in human infants. $J$ Neurosci 2006; 26: 3662-3666, doi: 10.1523/JNEUROSCI.0348-06.2006. human milk, its multiple advantages far outweigh this limitation (38).

The final concern is whether the administration of sucrose in association with painful procedures could stimulate the behavior of seeking sweet food for comfort and support in coping with other stressful experiences. If this association was established, this could provoke subsequent obesity and behavioral disorders in children that were born preterm. Unfortunately, the design of the present study could not address questions concerning long-term impact. However, our findings suggest that, during the short-term hospitalization period, the infants in the SG had weights similar to those in the CG.

In conclusion, oral sucrose $(0.5 \mathrm{~mL} / \mathrm{kg}$ of a $25 \%$ solution, $2 \mathrm{~min}$ prior to acute painful procedures) for pain relief in preterm neonates was effective and safe, exhibiting no short-term adverse effects in weight gain and feeding patterns, during hospitalization and postdischarge. However, the present study has some limitations. This was an exploratory study about the effects of sucrose on feeding pattern outcomes, using secondary data. The schedule of three consecutive days for sucrose administration could be insufficient to show significant differences between groups. The sample was small and the data could have been underreported in medical chart recordings.

In spite of these limitations, this is the first study to analyze the potential short-term side effects of sucrose for pain relief on the growth and feeding pattern outcomes of infants. The present study included a convenient sample of vulnerable neonates with several criteria for inclusion and exclusion in the study. These criteria were strong factors regarding methodological care; however, their use limited the sample size of infants. The current study was ecologically valid because the sample population was assessed in the natural setting of the NICU, allowing for the generalization of findings for similar samples and conditions.

Future studies are needed to analyze the growth and feeding patterns in a larger sample, and also to follow preterm infants who receive sucrose for pain relief during their entire time of long-term hospitalization.

\section{Acknowledgments}

We are very thankful to the families for participating in the study. Research supported by FAPESP (Process \#2011/50788-8) and CNPq.
3. Slater R, Cantarella A, Franck L, Meek J, Fitzgerald M. How well do clinical pain assessment tools reflect pain in infants? PLoS Med 2008; 5: e129, doi: 10.1371/journal.pmed. 0050129.

4. Anand KJ, Hall RW. Controversies in neonatal pain: an introduction. Semin Perinatol 2007; 31: 273-274, doi: 10.1053/ 
j.semperi.2007.07.014.

5. Valeri BO, Gaspardo CM, Martinez FE, Linhares MB. Does the neonatal clinical risk for illness severity influence pain reactivity and recovery in preterm infants? Eur J Pain 2012; 16: 727-736, doi: 10.1002/j.1532-2149.2011.00037.x.

6. Grunau RE, Holsti L, Haley DW, Oberlander T, Weinberg J, Solimano $A$, et al. Neonatal procedural pain exposure predicts lower cortisol and behavioral reactivity in preterm infants in the NICU. Pain 2005; 113: 293-300, doi: 10.1016/ j.pain.2004.10.020.

7. Lucas-Thompson R, Townsend EL, Gunnar MR, Georgieff MK, Guiang SF, Ciffuentes RF, et al. Developmental changes in the responses of preterm infants to a painful stressor. Infant Behav Dev 2008; 31: 614-623, doi: 10.1016/ j.infbeh.2008.07.004.

8. Corbo MG, Mansi G, Stagni A, Romano A, van den Heuvel J, Capasso L, et al. Nonnutritive sucking during heelstick procedures decreases behavioral distress in the newborn infant. Biol Neonate 2000; 77: 162-167, doi: 10.1159/ 000014211

9. Leite AM, Linhares MB, Lander J, Castral TC, dos Santos CB, Silvan Scochi CG. Effects of breastfeeding on pain relief in full-term newborns. Clin J Pain 2009; 25: 827-832, doi: 10.1097/AJP.0b013e3181b51191.

10. Holsti L, Oberlander TF, Brant R. Does breastfeeding reduce acute procedural pain in preterm infants in the neonatal intensive care unit? A randomized clinical trial. Pain 2011; 152: 2575-2581, doi: 10.1016/j.pain.2011.07.022.

11. Castral TC, Warnock F, Leite AM, Haas VJ, Scochi CG. The effects of skin-to-skin contact during acute pain in preterm newborns. Eur J Pain 2008; 12: 464-471, doi: 10.1016/ j.ejpain.2007.07.012.

12. Cong X, Ludington-Hoe SM, McCain G, Fu P. Kangaroo Care modifies preterm infant heart rate variability in response to heel stick pain: pilot study. Early Hum Dev 2009; 85: 561-567, doi: 10.1016/j.earlhumdev.2009.05.012.

13. Chermont AG, Falcao LF, de Souza Silva EH, de Cassia Xavier Balda R, Guinsburg R. Skin-to-skin contact and/or oral $25 \%$ dextrose for procedural pain relief for term newborn infants. Pediatrics 2009; 124: e1101-e1107, doi: 10.1542/peds.2009-0993.

14. Akcam M. Oral fructose solution as an analgesic in the newborn: a randomized, placebo-controlled and masked study. Pediatr Int 2004; 46: 459-462, doi: 10.1111/j.1442200x.2004.01932.x.

15. Ogawa S, Ogihara T, Fujiwara E, Ito K, Nakano M, Nakayama $\mathrm{S}$, et al. Venepuncture is preferable to heel lance for blood sampling in term neonates. Arch Dis Child Fetal Neonatal Ed 2005; 90: F432-F436, doi: 10.1136/ adc. 2004.069328.

16. Stevens B, Yamada J, Beyene J, Gibbins S, Petryshen P, Stinson J, et al. Consistent management of repeated procedural pain with sucrose in preterm neonates: Is it effective and safe for repeated use over time? Clin J Pain 2005; 21: 543548, doi: 10.1097/01.ajp.0000149802.46864.e2.

17. Lefrak L, Burch K, Caravantes R, Knoerlein K, DeNolf N, Duncan J, et al. Sucrose analgesia: identifying potentially better practices. Pediatrics 2006; 118 (Suppl 2): S197S202, doi: 10.1542/peds.2006-0913R.

18. Gaspardo CM, Miyase $\mathrm{Cl}$, Chimello JT, Martinez FE, Martins Linhares MB. Is pain relief equally efficacious and free of side effects with repeated doses of oral sucrose in preterm neonates? Pain 2008; 137: 16-25, doi: 10.1016/ j.pain.2007.07.032.

19. Stevens B, Yamada J, Ohlsson A. Sucrose for analgesia in newborn infants undergoing painful procedures. Cochrane Database Syst Rev 2010; CD001069.

20. Harrison D, Beggs S, Stevens B. Sucrose for procedural pain management in infants. Pediatrics 2012; 130: 918-925, doi: 10.1542/peds.2011-3848.

21. Batton DG, Barrington KJ, Wallman C. Prevention and management of pain in the neonate: an update. Pediatrics 2006; 118: 2231-2241, doi: 10.1542/peds.2006-2277.

22. Harrison D. Oral sucrose for pain management in infants: myths and misconception. J Neonatal Nursing 2008; 14: 3946, doi: 10.1016/j.jnn.2007.12.002.

23. Lago P, Garetti E, Merazzi D, Pieragostini L, Ancora G, Pirelli A, et al. Guidelines for procedural pain in the newborn. Acta Paediatr 2009; 98: 932-939, doi: 10.1111/ j.1651-2227.2009.01291.x.

24. Abad F, Diaz-Gomez NM, Domenech E, Gonzalez D, Robayna M, Feria M. Oral sucrose compares favourably with lidocaine-prilocaine cream for pain relief during venepuncture in neonates. Acta Paediatr 2001; 90: 160 165, doi: 10.1111/j.1651-2227.2001.tb00278.x

25. Bilgen H, Ozek E, Cebeci D, Ors R. Comparison of sucrose expressed breast milk, and breast-feeding on the neonatal response to heel prick. J Pain 2001; 2: 301-305, doi: 10.1054/jpai.2001.23140.

26. Johnston CC, Stremler R, Horton L, Friedman A. Effect of repeated doses of sucrose during heel stick procedure in preterm neonates. Biol Neonate 1999; 75: 160-166, doi: 10.1159/000014092.

27. Mitchell A, Stevens B, Mungan N, Johnson W, Lobert S, Boss $B$. Analgesic effects of oral sucrose and pacifier during eye examinations for retinopathy of prematurity. Pain Manag Nurs 2004; 5: 160-168, doi: 10.1016/j.pmn.2004.06.001.

28. Johnston CC, Filion F, Snider L, Majnemer A, Limperopoulos C, Walker CD, et al. Routine sucrose analgesia during the first week of life in neonates younger than 31 weeks' postconceptional age. Pediatrics 2002; 110: 523-528, doi: 10.1542/peds.110.3.523.

29. Boyer K, Johnston C, Walker CD, Filion F, Sherrard A. Does sucrose analgesia promote physiologic stability in preterm neonates? Biol Neonate 2004; 85: 26-31, doi: 10.1159/ 000074954.

30. Cignacco E, Denhaerynck K, Nelle M, Buhrer C, Engberg S. Variability in pain response to a non-pharmacological intervention across repeated routine pain exposure in preterm infants: a feasibility study. Acta Paediatr 2009; 98: 842-846, doi: 10.1111/j.1651-2227.2008.01203.x.

31. Johnston CC, Filion $F$, Snider L, Limperopoulos $C$, Majnemer A, Pelausa E, et al. How much sucrose is too much sucrose? Pediatrics 2007; 119: 226, doi: 10.1542/ peds.2006-3001.

32. Gaspardo CM, Linhares MB, Martinez FE. [The efficacy of sucrose for the relief of pain in neonates: a systematic review of the literature]. J Pediatr 2005; 81: 435-442, doi: 10.2223/JPED.1417.

33. Thureen PJ, Hay WW Jr. Intravenous nutrition and postnatal growth of the micropremie. Clin Perinatol 2000; 27: 197219, doi: 10.1016/S0095-5108(05)70014-2. 
34. Goubet N, Clifton RK, Shah B. Learning about pain in preterm newborns. J Dev Behav Pediatr 2001; 22: 418-424, doi: 10.1097/00004703-200112000-00009.

35. Holsti L, Grunau RE, Whifield MF, Oberlander TF, Lindh V. Behavioral responses to pain are heightened after clustered care in preterm infants born between 30 and 32 weeks gestational age. Clin J Pain 2006; 22: 757-764, doi: 10.1097/ 01.ajp.0000210921.10912.47.

36. Gaspardo CM, Chimello JT, Cugler TS, Martinez FE,
Linhares MB. Pain and tactile stimuli during arterial puncture in preterm neonates. Pain 2008; 140: 58-64, doi: 10.1016/ j.pain.2008.07.004.

37. Romero R, Kleinman RE. Feeding the very low-birth-weight infant. Pediatr Rev 1993; 14: 123-132, doi: 10.1542/pir.144-123.

38. American Academy of Pediatrics. Section on breastfeeding. Breastfeeding and the use of human milk. Pediatrics 2012; 129: e827-e841, doi: 10.1542/peds.2011-3552. 